\title{
EDITORIAL
}

\section{Should all ICU clinicians regularly be tested for burnout? Yes}

\author{
Laurent Papazian ${ }^{1,2^{*}}$, Aude Sylvestre $^{1,2}$ and Margaret Herridge ${ }^{3}$
}

(0) 2018 Springer-Verlag GmbH Germany, part of Springer Nature and ESICM

Intensive care unit (ICU) admissions are unplanned emergencies where ICU professionals are required to rapidly attend to complicated situations with uncertain outcomes. The interprofessional team is immersed in a complex milieu of heightened stress and intense emotion as they engage in a medical crisis with the patient and family. This is further compounded by a work environment that has become increasingly technical with its demand of extended skills in advanced life-sustaining therapies. A growing body of evidence suggests that burnout among ICU nurses [1] and ICU physicians [2] is the direct consequence of this demanding and inexorably high-stress work environment. Severe burnout-related symptoms are prevalent and have been reported in onethird of ICU nursing staff and one-half of ICU intensivists [1-3]. Burnout in healthcare workers may profoundly affect their well-being and the quality of professional care they provide and, therefore, may represent an important, and potentially modifiable, patient safety concern. Indeed, burnout has been identified as a key determinant of medical error in physicians [4] and has become a priority issue in our specialty and focus of a recent joint statement of the Critical Care Societies Collaborative [3].

There are several well-characterized risk factors that are associated with burnout symptoms. It has been shown that caregiving professional age is inversely associated with burnout [5], suggesting that younger caregivers may be more vulnerable to job burnout. It is highly plausible that caregivers with less seniority are still learning to cope with high workload demands when faced with stressors. Further, younger, female workers

\footnotetext{
*Correspondence: laurent.papazian@ap-hm.fr

${ }^{2}$ Médecine Intensive-Réanimation, APHM, Hôpital Nord, Chemin des Bourrely, 13015 Marseille, France

Full author information is available at the end of the article

For contrasting viewpoints, please go to https://doi.org/10.1007/s00134018-5139-3 and https://doi.org/10.1007/s00134-018-5169-x.
}

may face significant personal stressors including childcare demands and challenges to work-life balance that may further exacerbate stress. In the ICU setting, burnout rates may also be driven by high workload, frequent changes in technology and guidelines, quality of working relations (conflict and miscommunication), ethical issues, and emotional challenges of dealing with critically ill patients and their families especially when caring for a dying patient [1].

Burnout may also contribute to "sick days" and longterm absenteeism leading to challenges with staff retention. Professionals may feel they have no option but to leave their jobs prematurely to preserve their own mental and physical health, with resultant economic burden.

Surveillance of burnout prevalence in the ICU is mandatory because it has been shown that burnout is strongly associated with depressive symptoms and staff turnover $[1,6]$. In a large European survey involving more than 28,000 nurses, a high burnout score was associated with nurses' intent to leave their work setting [7]. The regular surveillance of these symptoms may prove valuable to facilitate the identification of nursing staff and ICU physicians who might benefit from additional support and to directly ascertain from interprofessional workers those potentially modifiable organizational factors they perceive to aggravate their symptoms. In a computer-based simulation of a 1-year schedule, a shared service schedule, in which the majority of overnight in-house coverage was provided by attendings who were also "on-service" during daytime, was predicted to increase the number of weeks attendings were free of clinical obligations and increased the number of weekend days off that attendings could spend on personal pursuits [8]. The shared service schedule may promote improved work-life balance by increasing the amount of time between clinical duties and the number of weekends off, both of which have been associated with decreased burnout and depression $[2,6]$.

\section{Springer}


Other suggested interventions include improving staffing levels; better communication, consultation, and collaboration; recognizing an individual's work; good leadership; and individualized interventions to confront risk factors. Cognitive behavioral therapy and relaxation techniques have also been suggested as effective strategies for coping with stressful environments. Prevention of conflicts is also a major issue. In the CONFLICUS international study [9], six factors associated with perceived conflicts were potential targets for intervention: staff working more than $40 \mathrm{~h} /$ week, more than 15 ICU beds, caring for dying patients or providing pre- and postmortem care within the last week, discordance in goals for symptom management between physicians and nurses, and no routine unit-level meetings. It remains uncertain, however, that there is a clear cause-effect relationship between conflict and burnout. Even if the occurrence of conflict at work has been identified as a major burnout risk factor in the literature [10], it is also highly plausible that ICU caregivers with burnout more often face conflict. It is therefore of paramount importance to ensure and promote interprofessional and team-based strategies (e.g., team meetings, quality improvement programs, clinical research activity) aimed at improving communication, organization, and shared vision. Interpersonal teamwork such as the quality of collaboration between nurses and physicians is a potential remediable goal. A recent longitudinal study [11] including 2100 nurses and physicians working in 55 Swiss ICUs showed that emotionally exhausted clinicians were less able to contribute to effective teamwork, which is critical to the maintenance of patient safety. Even in high technology environments such as the ICU setting, good interpersonal relationships may facilitate cognitive behavioral teamwork. Thus, interventions targeting a healthy teamwork dynamic should focus on establishing shared goals and priorities and enhanced communication and coordination. A recent small randomized clinical trial [12] evaluated if protected time ( $1 \mathrm{~h}$ of paid time every other week) provided by the institution would be able to promote well-being and reduce distress in physicians. The intervention involved facilitated physician discussion groups based on elements of mindfulness, reflection, shared experience, and smallgroup learning intended to promote collegiality and community at work among participants. Although there was not an important reduction in emotional exhaustion and overall burnout with this intervention, there was a significant decrease $(15.5 \%)$ in the rate of depersonalization at 3 months after study completion. Furthermore, this difference was sustained at 12 months. The implementation of an active, intensive communication strategy regarding end-of-life care in the ICU has also been shown to be associated with a significant reduction in the rate of burnout in a before-after study [13]. Burnout has also been viewed as a contagious syndrome [14] and therefore it is crucial to stem the propagation of burnout when there is an identified increase in prevalence. Identification of the causes explaining this rise may lead to specific interventions by hospital managers, nursing leadership, and ICU directors. Indeed, excessive staff turnover rates reduce the overall quality of care, decrease productivity, lower staff self-esteem, and, because experienced professionals who leave their workplaces must be replaced, promote increased healthcare costs [15].

All these data support the necessity to screen and to act promptly and definitively when burnout is recognized.

\section{Author details \\ ${ }^{1}$ Centre d'Etudes et de Recherches sur les Services de Santé et qualité de vie EA3279, Aix-Marseille Université, Marseille, France. ${ }^{2}$ Médecine Intensive-Réan- imation, APHM, Hôpital Nord, Chemin des Bourrely, 13015 Marseille, France. \\ ${ }^{3}$ University of Toronto, Interdepartmental Division of Critical Care Medicine, University Health Network, 11 Munk-1180, 585 University Avenue, M5G 2N2 Toronto, ON, Canada.}

Compliance with ethical standards

Conflicts of interest

No conflict of interests.

Received: 7 February 2018 Accepted: 9 February 2018 Published online: 7 May 2018

\section{References}

1. Poncet MC, Toullic P, Papazian L, Kentish-Barnes N, Timsit JF, Pochard F, Chevret S, Schlemmer B, Azoulay E (2007) Burnout syndrome in critical care nursing staff. Am J Respir Crit Care Med 175:698-704

2. Embriaco N, Azoulay E, Barrau K, Kentish N, Pochard F, Loundou A, Papazian $L$ (2007) High level of burnout in intensivists: prevalence and associated factors. Am J Respir Crit Care Med 175:686-692

3. Moss M, Good VS, Gozal D, Kleinpell R, Sessler CN (2016) A critical care societies collaborative statement: burnout syndrome in critical care health-care professionals. A call for action. Am J Respir Crit Care Med 194:106-113

4. Hall LH, Johnson J, Watt I, Tsipa A, O'Connor DB (2016) Healthcare staff wellbeing, burnout, and patient safety: a systematic review. PLoS One 11:e0159015

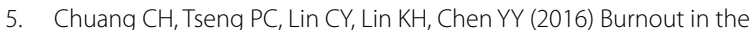
intensive care unit professionals: a systematic review. Medicine (Baltimore) 95:e5629

6. Embriaco N, Hraiech S, Azoulay E, Baumstarck-Barrau K, Forel JM, KentishBarnes N, Pochard F, Loundou A, Roch A, Papazian L (2012) Symptoms of depression in ICU physicians. Ann Intensive Care 2:34

7. Estryn-Behar M, Van der Heijden BI, Oginska H, Camerino D, Le Nezet O, Conway PM, Fry C, Hasselhorn HM, Group NS (2007) The impact of social work environment, teamwork characteristics, burnout, and personal factors upon intent to leave among European nurses. Med Care 45:939-950

8. Geva A, Landrigan CP, van der Velden MG, Randolph AG (2017) Simulation of a novel schedule for intensivist staffing to improve continuity of patient care and reduce physician burnout. Crit Care Med 45:1138-1144

9. Azoulay E, Timsit JF, Sprung CL, Soares M, Rusinova K, Lafabrie A, Abizanda R, Svantesson M, Rubulotta F, Ricou B, Benoit D, Heyland D, Joynt G, Francais A, Azeivedo-Maia P, Owczuk R, Benbenishty J, de Vita M, Valentin A, Ksomos A, Cohen S, Kompan L, Ho K, Abroug F, Kaarlola A, Gerlach H, 
Kyprianou T, Michalsen A, Chevret S, Schlemmer B, Conflicus Study I, for the Ethics Section of the European Society of Intensive Care Medicine (2009) Prevalence and factors of intensive care unit conflicts: the Conflicus study. Am J Respir Crit Care Med 180:853-860

10. Embriaco N, Papazian L, Kentish-Barnes N, Pochard F, Azoulay E (2007) Burnout syndrome among critical care healthcare workers. Curr Opin Crit Care 13:482-488

11. Welp A, Meier LL, Manser T (2016) The interplay between teamwork, clinicians' emotional exhaustion, and clinician-rated patient safety: a longitudinal study. Crit Care 20:110

12. West CP, Dyrbye LN, Rabatin JT, Call TG, Davidson JH, Multari A, Romanski SA, Hellyer JM, Sloan JA, Shanafelt TD (2014) Intervention to promote physician well-being, job satisfaction, and professionalism: a randomized clinical trial. JAMA Intern Med 174:527-533

13. Quenot JP, Rigaud JP, Prin S, Barbar S, Pavon A, Hamet M, Jacquiot N, Blettery B, Herve C, Charles PE, Moutel G (2012) Suffering among carers working in critical care can be reduced by an intensive communication strategy on end-of-life practices. Intensive Care Med 38:55-61

14. Bakker AB, Le Blanc PM, Schaufeli WB (2005) Burnout contagion among intensive care nurses. J Adv Nurs 51:276-287

15. Reader TW, Cuthbertson BH, Decruyenaere J (2008) Burnout in the ICU: potential consequences for staff and patient well-being. Intensive Care Med 34:4-6 